\title{
Multistatic estimation of high-frequency radar surface currents in the region of Toulon
}

\author{
Dumas Dylan ${ }^{1}$, Gramoullé Annie ${ }^{1}$, Guérin Charles-Antoine ${ }^{1,}{ }^{*}$, Molcard Anne ${ }^{1}$, Ourmières Yann ${ }^{1}$, \\ Zakardjian Bruno ${ }^{1}$
}

\author{
${ }^{1}$ Mediterranean Institute of Oceanography, Université de Toulon, Aix Marseille Univ, CNRS, IRD, MIO, \\ Toulon, France \\ * Corresponding author : Charles-Antoine Guérin, email address : guerin@univ-tln.fr
}

\begin{abstract}
:
The high-frequency radar coastal network in Toulon operates in multistatic mode for the monitoring of the ocean circulation in the Northwestern Mediterranean Sea. With 2 transmitters and 2 receivers on 3 distant sites, it measures 4 different elliptical components of the surface velocity. We provide a methodology for improved current mapping using this augmented number of available projections and we show some typical results obtained during the year 2019. The validity and the quality of the reconstruction are assessed through comparisons with two types of in situ measurements, namely drifters' velocities from a dedicated campaign and acoustic Doppler current profiler data from an opportunity oceanographic campaign. The results of these assessments confirm the accuracy of these high-frequency radar measurements and their ability to capture the meso- to submeso-scale variability of the near shelf circulation.
\end{abstract}

Keywords : High-frequency radar, Surface current, Multistatic, Drifters 


\section{Introduction}

The ever increasing demand for real-time monitoring of surface currents in coastal area has supported a constant growth of High-Frequency Radar (HFR) coastal networks around the world in the last decade with over 400 stations installed (Roarty et al (2019)). The vast majority of these radar systems operate in monostatic mode (i.e. with colocated transmitter and receiver) which is the standard on-the-shelf configuration. However, it has been realized for about one decade that bistatic (i.e. with separated transmitter and receiver) and multistatic (i.e. with multiple interacting transmitters and receivers) modes can be very advantageous configurations to mitigate some practical limitations of existing monostatic installations (Lipa et al (2009); Whelan and Hubbard (2015); Baskin et al (2016); Roarty et al (2019); Yang et al (2014); Guérin et al (2019); Dumas and Guérin (2020)). The main reason is that the larger number of available projections

Université de Toulon, Aix Marseille Univ., CNRS, IRD, MIO UM110, La Garde, France. Email: (dylan.dumas,gramoulle,guerin,molcard,ourmieres,zakardjian)@univ-tln.fr 
of the surface velocity and their redundancy make it possible to increase the accuracy of the surface current as well as the radar coverage; in addition, multistatic systems are more robust to hardware failure which is a common struggle to radar operators.

Our group has been operating for one decade a HFR network for the monitoring of surface currents in the coastal area of Toulon (e.g. Marmain et al (2011, 2014); Bellomo et al (2015); Sentchev et al (2017)). In this region, the circulation is dominated by a strong permanent westward boundary current, referred to as the "Northern Current" (NC), a major large-scale hydro-dynamical feature of the Northwestern Mediterranean (Millot and Taupier-Letage (2005)). The NC flows all along the Italian and French coasts down to the Balearic Sea off Spain with a mass transport of 1.0-2.0 Sverdrup $\left(10^{6} \mathrm{~m}^{3} / \mathrm{s}\right)$ and a significant seasonal variability with lowest (highest) transports in summer (winter) (e.g. Millot and Taupier-Letage (2005)). Due to a narrow continental shelf in the vicinity of Toulon, the main vein of the NC flows at a small distance from shore $(20-30 \mathrm{~km})$, hence generally well under the HFR coverage area so that its spatial patterns can be continuously monitored. Some remarkable improvements of the local HFR network have been achieved recently in the framework of the Interreg Marittimo EU project SICOMAR-PLUS, both on the hardware and software levels (Guérin et al (2019); Dumas and Guérin (2020)) and the system is now running in multistatic mode as of January 2019. The present study provide the first detailed results and analyses of this multistatic configuration and its ability to better monitor the high frequency (hourly to daily estimates) to monthly variability of the circulation.

The specificity of bistatic geometry for surface current extraction and the experimental set-up are described in Section 2. The quality of the different elliptical velocities can be quantified by a usual Signal-to-Noise Ratio (SNR) criterion for the first-order Bragg lines in the bistatic Doppler spectrum. Statistical analyses of the SNR (Section 3) show that 2 radials are optimal (henceforth referred to as "primary") for current vector reconstruction inasmuch as the corresponding SNR displays large values over a wide area. The 2 remaining components are of lesser quality according to the same standard (henceforth referred to as "secondary"). Analysis of the Geometrical Dilution of Precision further shows that the primary radials are also geometrically optimal for the vector reconstruction while the addition of secondary radials can only improve the reconstruction in a restricted area of the map. This a priori appraisal of the different radials is confirmed by actual mapping total velocity. We show that complementing the vector reconstruction with secondary radials allows to correct for the deficiency of primary radial in some specific areas with very little improvement elsewhere. Nevertheless, secondary radials are found useful for an estimation of accuracy based on a reconstruction/reprojection technique as well as a last resort for vector mapping in case of a missing primary radial due to hardware failure. The actual accuracy of the 4 radials is assessed through experimental comparisons with 5 launches of surface drifters (Section 5). For the 3 trajectories that have the largest intersection with the radar coverage, an excellent agreement is found for the primary radials with a Root Mean Square Difference (RMSD) of the order of $2.5 \mathrm{~cm} / \mathrm{s}$ and $3-5 \mathrm{~cm} / \mathrm{s}$, respectively while as expected the secondary radials show satisfying performance in restricted areas only. A more synoptic view of the performances of HFR surface current mapping is provided in Section 6, where opportunity ADCP measurements from a one-day oceanographic 
campaign are compared with instantaneous and daily-averaged estimates of HFR currents.

\section{Material and data}

2.1 The multistatic HFR network in Toulon

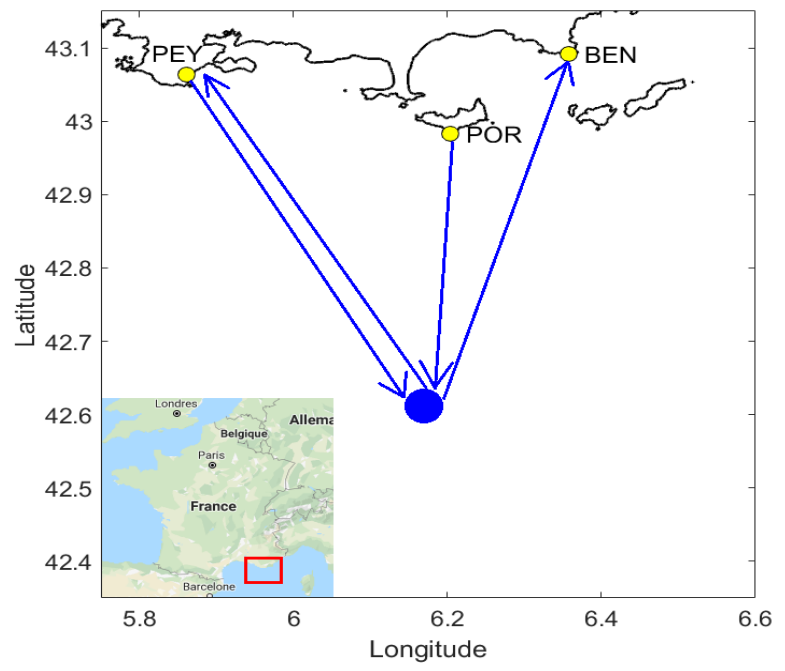

Fig. 1 - The three HFR sites in the region of Toulon: 1) Fort Peyras (TX/RX, "PEY"); 2) Cap Bénat (RX, "BEN"); 3) Porquerolles Island (TX, "POR").

The HFR network in Toulon is manufactured by WERA Helzel Messtecknik and operates at a carrier frequency $f=16.150 \mathrm{MHz}$. It is composed of 2 transmitters (TX) and 2 receivers (RX) located on three distant sites, referred to as POR, PEY and BEN (Figure 1). A standalone transmitter is located on Porquerolles Island (POR) $27 \mathrm{~km}$ South-East of Toulon and illuminates a wide area to the South with one single, nondirectional, emitting antenna. A first array of 12 receiving antennas is located at Cap Bénat, $35 \mathrm{~km}$ East of Toulon (BEN) with a main array axis oriented 70 degrees from North, anticlockwise. The second transmitter and receiver are located at Fort Peyras (PEY) about $8 \mathrm{~km}$ South West of Toulon. The transmitter uses 2 coupled antennas allowing for a dominant emission to the East. The receiving array is composed as a non-regular arrangement of 8 passive antennas with the main longest direction oriented 5 deg from North anticlockwise $^{1}$. We refer to Guérin et al (2019); Dumas and Guérin (2020) for a more detailed description of the installation. The historical HFR network has been operated over the period 2012-2018 using only the monostatic pair PEY-PEY and the bistatic pair POR-BEN (Quentin et al (2013)). Since 2019 it is operated in

1. As of January 2020, the receiving array has been upgraded to a regular array of 12 antennas 
a fully multistatic configuration with the 2 transmitters and 2 receivers working synchronously. This gives access to 4 different projections of the surface velocity which are referred to as "elliptical velocities" and will sometimes simply termed as "radials" by analogy with the standard monostatic case.

2.2 A dedicated drifter campaign

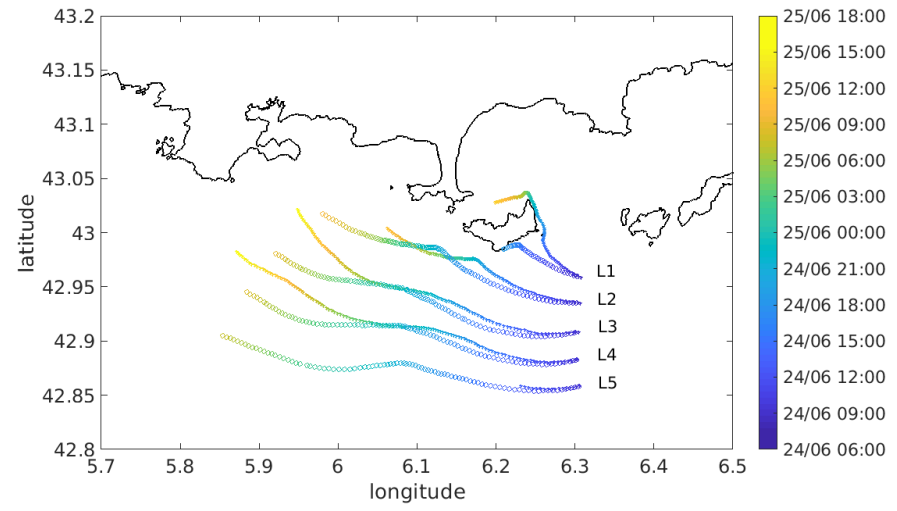

Fig. 2 - Trajectories of the carthe (stars) and surfy (circles) drifters. For each type of drifter, the launches are labeled from L1 to L5 starting from North along the meridional section 6.3 deg $E$ The colorbar represents the time evolution.

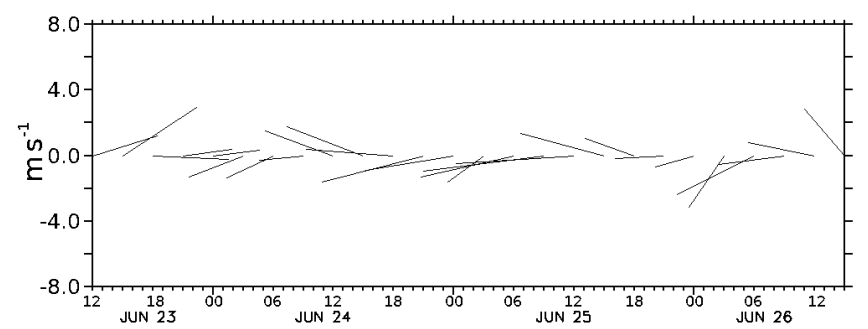

FIG. 3 - Stick diagram of the wind averaged over the region covered by the drifters trajectories, data from MeteoFrance ARPEGE model.

It is now customary to assess the HFR surface current measurement by comparison with drifting buoys, or drifters (Chapman et al (1997); Paduan et al (2006); Ohlmann and et. al (2007); Molcard et al (2009); Rypina et al (2014); Bellomo et al (2015); Shadden et al (2009); Kalampokis et al (2016); Sentchev et al (2017); Morey et al (2018); Kirincich et al (2019); Capodici et al (2019)). Several lessons can be drawn from this extensive bibliography about the ability of the HFR to 
measure the surface currents, as well as about the validity of the drifter-radar comparison. The two platforms (HFR and surface drifters) are able to measure the surface current velocities, but some differences are expected due to the instrument and the sampling method. The HFR gives vertically averaged values from the surface to a depth depending on the radar frequency, horizontally averaged values over the grid size (several $\mathrm{km} 2$ for the HFR) and temporally averaged over the integration period (1 hour). Drifters follow the surface currents integrated over their drag elements, feel the velocity at a spatial scale corresponding to their size (order of meter) and may be subject to windage and Stokes drift (Novelli et al (2017); Lumpkin et al (2017); Novelli et al (2018); Morey et al (2018)). The shape of the buoy and the depth of the drogue should then be considered when computing current velocities, as the comparison with HFR data may result in large discrepancies. For example, comparison with drifters drogued at deeper depths than the effective depth of the radars (Capodici et al (2019); Paduan et al (2006)) can lead to velocity differences higher than $10 \mathrm{~cm} / \mathrm{s}$, especially under strong vertical shear. Published velocity comparisons between HFR surface currents velocities and drifters drogued at radar equivalent depth, range from RMSD of 5 to 10 cm/s (Ohlmann and et. al (2007); Molcard et al (2009); Bellomo et al (2015); Rypina et al (2014)). These discrepancies can be considered acceptable as within the bounds of expected variability, due to spatial and temporal mismatch of scales (Ohlmann and et. al (2007)) and instrument resolution.

In order to validate the surface current velocity measured by the radar, a seatrial experiment has been conducted by deploying surface floating buoys south of Porquerolles Island, within the radars coverage area. The successive drifters GPS positions are transmitted by Iridium satellite telemetry at regular frequency, and the Lagrangian velocity is computed and considered as the ground truth (Enrile et al (2018)). For this experiment, we use a novel GPS biodegradable drifter design that was developed under the Consortium for Advanced Research on Transport of Hydrocarbon in the Environment (CARTHE), and have been used successfully in a number of experiments in the Gulf of Mexico (e.g., Lumpkin et al (2017), Özgökmen et al (2018)). The drifter extends to a depth of $60 \mathrm{~cm}$ and is designed to follow the surface-ocean flow field such that the influence of waves and winds is minimized (Novelli et al (2017); Lumpkin et al (2017); Novelli et al (2018)). The GPS returns a position every $5 \mathrm{~min}$, accurate to within $6 \mathrm{~m}$. Another drifter design has been tested during the experiment, the surfy drifter. The $20 \mathrm{~cm}$ diameter hull has a spherical shape (Albatros manufactured ${ }^{2}$ ), and is almost entirely immersed, resulting in a small windage. However the size and shape of this type of float make it more sensitive to Stokes drift (Lumpkin et al (2017); Novelli et al (2018)). The GPS returns a position every 10 minutes using Globalstar satellite coverage.

The experiment was conducted from the 24th to the 25th of June 2019, 5 deployment positions were chosen regularly spaced along a meridional section (at $6.3 \mathrm{deg}$ E) crossing the NC, and the 2 drifters type were simultaneously deployed at each position. The resulting trajectories are plotted in Figure 2, and are very consistent with the circulation of the region (Declerck et al (2016)). A strong easterly wind was blowing during these 2 days (Figure 3), reinforcing the westward boundary current, and resulting in a drifter mean velocity of $0.5 \mathrm{~m} / \mathrm{s}$ for the surfy drifters and $0.4 \mathrm{~m} / \mathrm{s}$ for the carthe ones. Consequently the drifter type experienced

2. https://static.gsattrack.com/hardware/manufacturers/albatros-marine-technologies 
different trajectories, as the pair separated very quickly, due to the vertical shear in the Ekman layer generated by the wind and potential Stokes drift influence.

\subsection{ADCP data from an opportunity oceanographic campaign}

In section 6 we will present a case study for the February 20, 2019 based on the comparisons of the HFR velocities with current measurements made from a vessel mounted ADCP off Toulon. This one day oceanographic cruise was made in the framework of the MOOSE-ANTARES observing program (Lefévre (2010)). The VM-ADCP is a $75 \mathrm{kHz}$ RDI Ocean Surveyor ADCP permanently operated from the Tethys- 2 vessel (CNRS/INSU). The ADCP works in narrow band mode with 70 cells of $8 \mathrm{~m}$ bins and a $2 \mathrm{~min}$ (38 pings) ensemble average. Data are operationally treated and saved in the framework of the SAVED database, a project from the French National Institute of Sciences of the Universe ${ }^{3}$. However, one must keep in mind that the comparisons of HFR surface velocities with current measurements from a $75 \mathrm{kHz} \mathrm{VM}-\mathrm{ADCP}$ on a moving vessel is not the best way to do such assessment. First, the two current velocity estimates can greatly differ given that the two instruments do not measure exactly the same physical quantities, have different spatio-temporal resolutions and specific measurement errors (e.g. Paduan and Rosenfeld (1996); Graber et al (1997); Robinson et al (2011); Sentchev et al (2017)). The HFR velocities are surface estimates (actually depthintegrated between 0 and $0.65 \mathrm{~m}$ depth, see section 5 ), averaged over time (1 hour) and space $\left(1 \mathrm{~km}^{2}\right.$ cells $)$. The ADCP are quasi-instantaneous measurements $(2 \mathrm{mi}-$ nutes integrated) of vertically averaged estimates over $8 \mathrm{~m}$ bins, starting for the first exploitable bin at $16.47 \mathrm{~m}$ in our case. The current intensity and direction can significantly change between the surface and $16 \mathrm{~m}$, mainly in response to short time wind effects (e.g Yoshikawa et al (2007); Sentchev et al (2017)) and the HFR measurements may include part of the Stokes' drift (Ardhuin et al (2009); Röhrs et al (2015)) that cannot be caught by the ADCP.

\section{Methodology of multistatic HFR reconstruction}

\subsection{Bistatic current extraction}

The principle of surface current extraction from HFR is by now well-known and documented and we refer to some review papers (e.g. Gurgel et al (1999); Paduan and Washburn (2013)) for a survey of the methods and applications. The main physical principle underlying this detection is the presence of a resonant wave at half the radar wavelength $(\lambda / 2)$, referred to as the Bragg wave. The dominant contribution of this wave to the backscattered radar signal produces a very marked peak in the Doppler spectrum at the so-called Bragg frequency, $f_{B}=$ $\sqrt{g / \pi \lambda}$, inferred from the dispersion relationship of the resonant gravity wave. Any observed shift $\Delta f$ of the main Doppler peak with respect to the Bragg frequency is attributed to the translation effect of a surface current $\boldsymbol{U}$; the magnitude of this shift can be converted into an algebraic value of the radial speed $U_{r}$ (i.e.,

3. http://saved.dt.insu.cnrs.fr/ 
projected along the radar line of sight) of the surface current $\left(U_{r}=\lambda \Delta f / 2\right)$. A radial surface current map can thus be obtained with one monostatic radar after range and azimuthal cell discrimination.

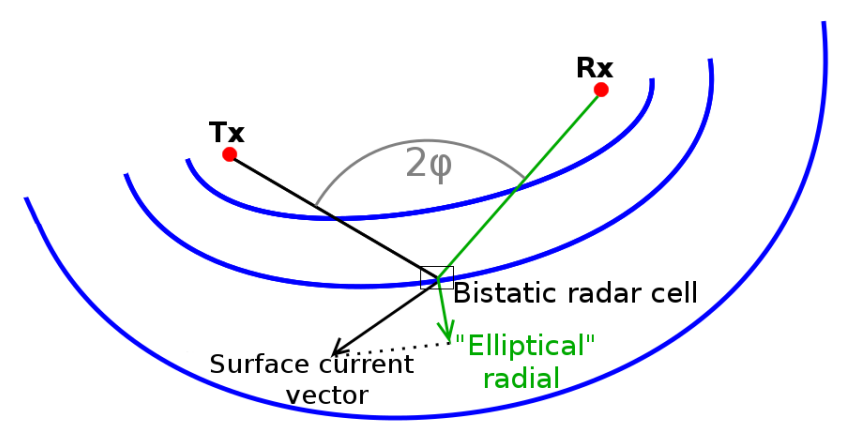

Fig. 4 - In the bistatic geometry the iso-range cells are located on ellipses with focii at the transmitter and receiver. The local Bragg frequency depends on the bistatic angle $\varphi$.

The bistatic geometry (e.g. Grosdidier et al (2014)) is more complicated in several respects: a) the iso-range radar cells follow ellipses (instead of circles) with focii at the transmitter and receiver locations; b) the Bragg frequency varies with the cell coordinates; c) the measured Doppler shift with respect to the Bragg frequency is related to the projection of the surface current vector onto the local normal to the ellipse, a component which we refer to as the "elliptical" radial (Figure 4). Due to the bistatic geometry and also due to the necessity to cope with several simultaneous transmitters the multistatic configuration requires specific processing techniques, which have been recently developed (Guérin et al (2019)). The azimuthal processing is performed with an improved Direction Finding (DF) algorithm (Dumas and Guérin (2020)) which allows to obtain high-resolution maps with a good filling ratio as shown in Figure 5.

A key parameter of the bistatic geometry is the so-called bistatic angle $\varphi$ depicted in Figure 4 which denotes the vertex angle of the triangle formed by the transmitter, radar cell and receiver. The monostatic case is recovered in the limiting case $\varphi=0$ where the cell range is much larger than the transmitter-receiver baseline and for those radar cells aligned with this baseline. The adaptation of the classical Bragg theory to the bistatic case leads to a non-constant resonant Bragg frequency:

$$
f_{B}(\varphi)=\sqrt{\frac{g \cos \varphi}{\pi \lambda}}
$$

Any observed Doppler shift $\Delta f$ with respect to this local Bragg frequency is now proportional to the projected component $U_{n}$ of the surface current vector $\boldsymbol{U}$ onto the normal direction to the ellipse:

$$
U_{n}=\frac{\lambda \Delta f}{2 \cos \varphi}
$$



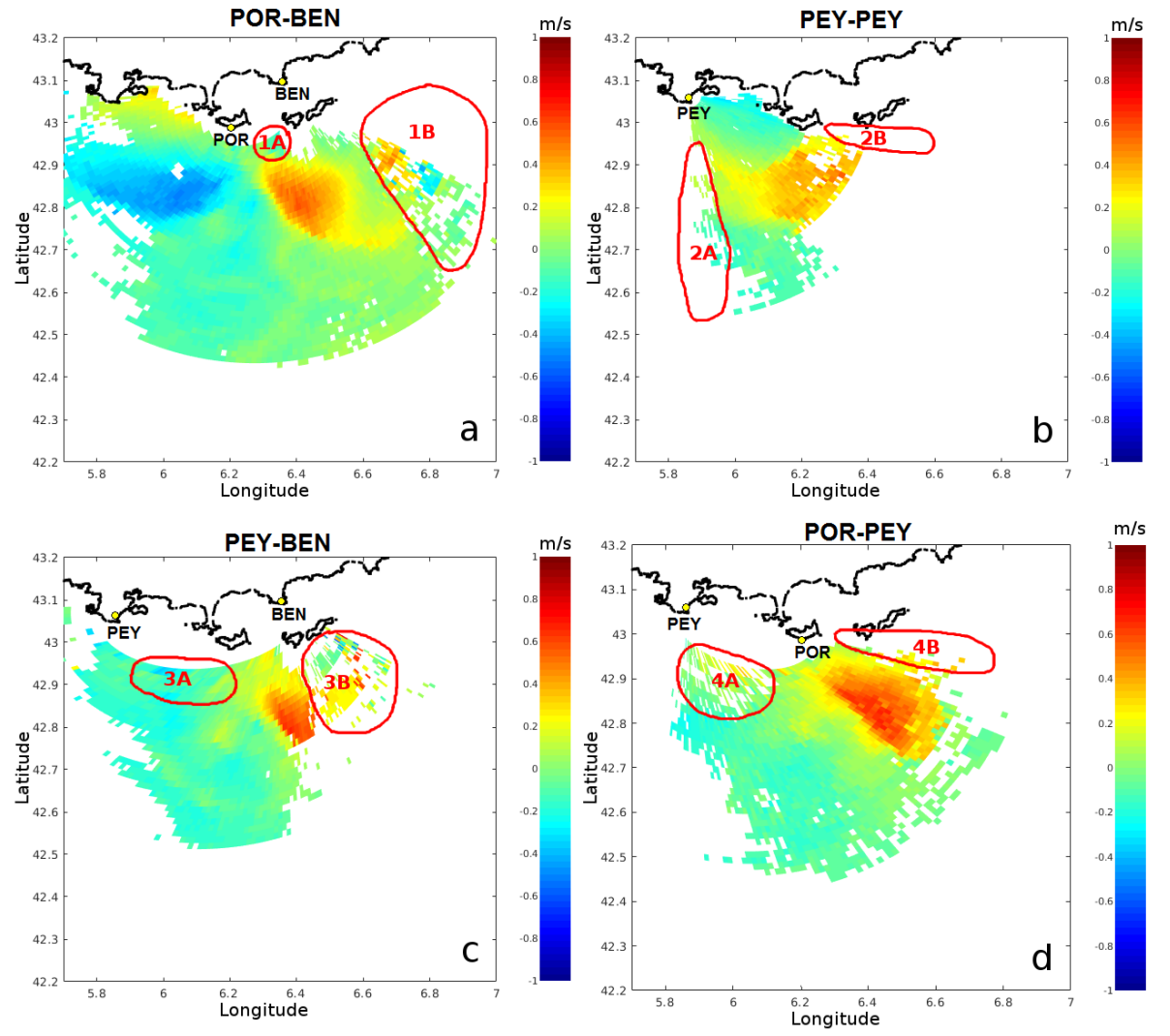

Fig. 5 - Four simultaneous elliptical velocities maps resulting from a 1 hour observation time on February 4, 2019 (14:00-15:00 UTC):a) POR-BEN b) PEY-PEY c) PEY-BEN d) POR$P E Y$. The red contours $1 A, 3 A$ and $4 A$ highlight the artifact of rapidly varying bistatic angles in near-range ellipses; the southward angular masking of the receive array in Fort Peyras in shown by the contour 2A; the land masking of the PEY-PEY radial is seen in contour $2 B$.

One important difference with the classical monostatic configuration is a varying Bragg frequency over the radar coverage (see eq. (1)). Now at close range, the bistatic angle $\varphi$ undergoes rapid variations when describing an iso-range ellipse. This can induce non-negligible variations of the Bragg frequency within a radar cell and cause a blurring of the azimuthally resolved Bragg peak in the Doppler spectrum. For this reason the first few elliptical velocity cells must be discarded.

The performances of the receiving networks in the respective directions of observations are also governed by the orientation of the antennas arrays. The main axis of the receiving array in Fort Peyras is almost aligned to the North so that it is optimally collecting to the East and is almost "blind" to the South. In a similar way, the antenna array in Cap Bénat does not sense to the East. 
(a)

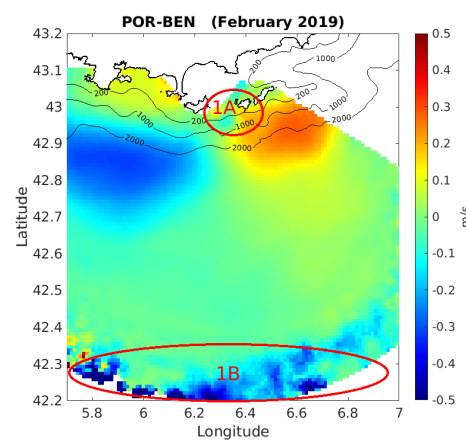

(c)

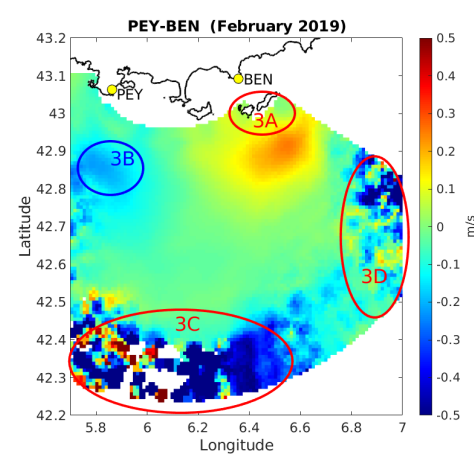

(b)

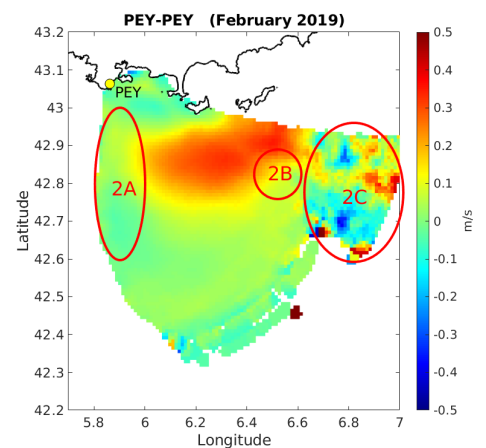

(d)

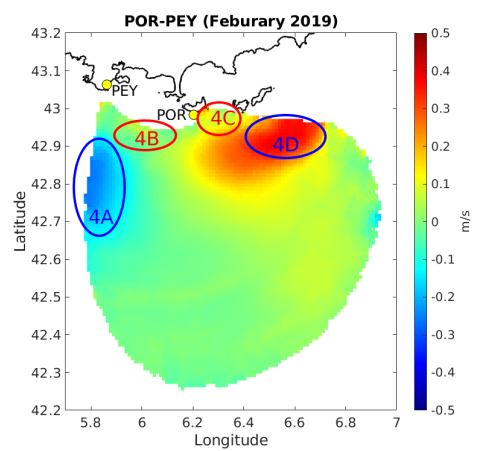

FiG. 6 - Averaged elliptical velocities resulting from one month observation (February 2019): a) POR-BEN b) PEY-PEY c) PEY-BEN d) POR-PEY. The geometrical artifacts of the multistatic configuration are highlighted by the red contours while the improvements brought by the secondary radials are marked in blue.

These defects due to geometrical limitations are highlighted by the red contours on the different maps in Figure 5. In the regions where the bistatic angle is rapidly varying corresponding to some portions of near-range ellipses, the estimation of current is degraded leading to spurious variations of the latter. This can be clearly seen on the radials POR-BEN (contour 1A), PEY-BEN (contour 3A) and PORPEY (contour 4A). The lack of southward measurements with the PEY-PEY radial is consistent with the angular cut-off of the receiving antenna array (contour 2A). Another limitation of both transmitting and receiving networks is the masking effect of islands when crossed in their longest dimension. This is the case for the backscattered signal measured in Fort Peyras, which is attenuated on its round trip to the East the by the Giens Peninsula and Porquerolles Island (contour 2B)

To obtain a better contrast between the reliable and corrupted surface current estimation, we also displayed in Figure 6 the same averaged radials over one month (February 2019). The geometrical artifacts of the multistatic configuration are highlighted by the red contours: $3 \mathrm{~A}, 4 \mathrm{~B}$ and $4 \mathrm{C}$ for the effect of rapidly varying bistatic angle; contour $2 \mathrm{~A}$ for the orientation of the receiving array in Fort Peyras. The side-effect of insufficient time coverage and SNR is marked by the contour 2B; the impact of $\mathrm{RFI}$ is visible in contours $2 \mathrm{C}, 3 \mathrm{C}, 3 \mathrm{D}$. Improvements brought by the 
secondary radials with respect to the aforementioned defects are marked in blue (3B, $4 \mathrm{~A}$ and $4 \mathrm{D})$.

3.3 Signal to Noise Ratio and temporal coverage

(a)

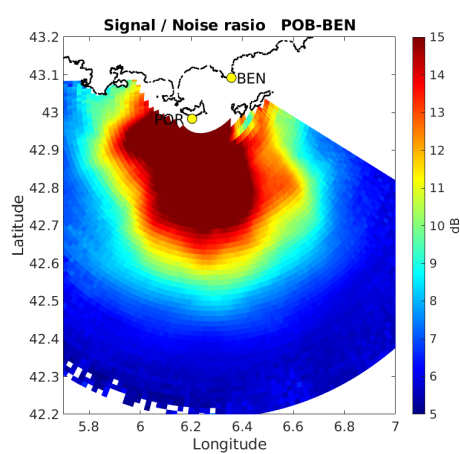

(c)

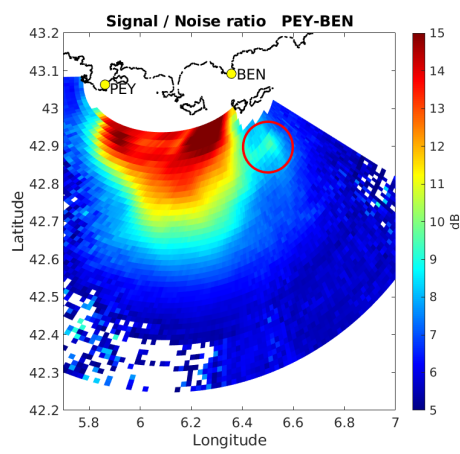

(b)

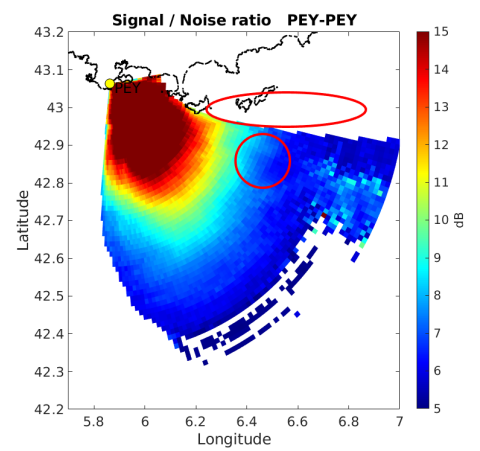

(d)

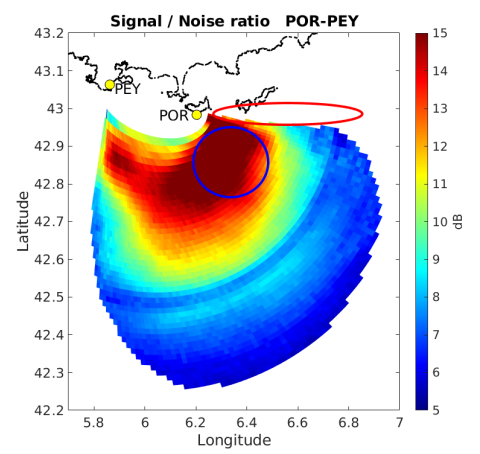

Fig. 7 - Average SNR (in $d B$ ) over the month of February 2019 for the four elliptical velocities. a) POR-BEN b) PEY-PEY c) PEY-BEN d) POR-PEY. (a) and (b) radials have the best overall SNR but (c) and (d) radials can bring marginal improvements in the vicinity of the islands and in the Eastern part of the radar coverage (blue circle in (d)). The drop of SNR due to land masking is clearly visible for the radials related to the Fort Peyras transmitter (red ellipses in (b) and (d)). The red circle in c) shows an isolated spot of higher SNR due to a free path between the islands. The red circle in b) shows an isolated spot of smaller SNR inducing locally a small drop of level of the mean current.

Another observation is that the different elliptical velocity maps shown in Figures 5 and 6 do not seem to share the same overall quality, as some maps are noisier and more lacunary. This is primarily due to the variation of Signal of Noise Ratio (SNR) in the received Power Spectral Density (PSD) associated to the different radar cells on the sea surface depending on the choice of the bistatic pairs. As was shown recently (Forget (2015)), the level of noise drives the actual temporal resolution with which the radial velocity can be measured and thus strongly impacts the accuracy of instantaneous measurements. 
The SNR in the context of HFR surface current estimation is usually defined as the ratio of the first-order Bragg peak of the PSD $\sigma(\omega)$ to its average level:

$$
S N R=\max _{\omega} \sigma(\omega) \times\left(\frac{1}{B} \int_{B} \sigma(\omega) d \omega\right)^{-1}
$$

We recall that from the bistatic radar equation (see e.g. Grosdidier et al (2014) for details) the PSD of the signal originating from a given patch of area $A$ on the sea surface is given by:

$$
\sigma(\omega)=P_{e} \frac{\lambda^{2}}{(4 \pi)^{3}} \frac{F_{t} G_{t} F_{r} G_{r}}{R_{t x}^{2} R_{r x}^{2}} A \tilde{\sigma}(\omega)
$$

where $P e$ is the transmitted power, $R_{t x}$ and $R_{r x}$ are the distance from patch to the transmitter and the receiver and the terms $F_{t}, F_{r}$ are the surface wave attenuation factor over the transmit and receive paths, respectively. Here, $\tilde{\sigma}(\omega)$ is the mean radar cross section per unit surface area per unit bandwidth, which is obtained statistically for an infinite surface in the well-known Bragg theory (Barrick $(1972 \mathrm{~b}, \mathrm{a}))$. As a result, bistatic pairs involving larger travel distances over the sea surface or a weaker transmitter have reduced SNR. Note that the classical definition (3) of the SNR involves individual radar cells and therefore only applies to Doppler spectra which are already resolved in range and azimuth, that is essentially those obtained after a beam-forming azimuthal processing. Nevertheless, the definition can be adapted to work in the case of DF algorithm, where only omnidirectional single-antenna Doppler spectra are available. To do this, the SNR of every spectral ray in the omnidirectional Doppler spectrum is attributed to the bearing found after application of the DF algorithm. In the elliptical velocity extraction procedure, only PSD with a SNR larger than $5 \mathrm{~dB}$ have been retained and the integration bandwidth for the mean Doppler spectrum has been set to $[-0.7+0.7] \mathrm{Hz}$ (because it is the effective support of the "full" Doppler spectrum with second-order components).

Figure 7 shows the resulting SNR using this definition. To enhance visibility, those SNR has been averaged over one month and only values larger than $5 \mathrm{~dB}$ have been retained. As clearly seen, the best overall levels of SNR are obtained with the POR-BEN radial and the second best with the PEY-PEY radial. The SNR of the last two radials, POR-PEY and PEY-BEN, is in general much poorer but is found relatively good in the vicinity of the islands as well as in the Eastern part of the radar coverage, where the first two radials, POR-BEN and PEY-PEY, are insufficient. Hence, it is quite obvious that the reconstruction of the surface current over the largest region can be performed with the best two radials POR-BEN and PEY-PEY (henceforth termed primary), while the secondary radials POR-PEY and PEY-BEN can be used to correct and complement the reconstruction in some specific areas.

Another key parameter to take into account when dealing with time-averaged maps is the temporal coverage, which we define as the proportion of SNR larger than the threshold value (here, $5 \mathrm{~dB}$ ) for every grid cell. The resulting maps (not shown here) are strongly correlated to the spatial distribution of SNR and confirm that the POR-BEN radial is by far the best performing. We found the PEY-PEY radial to be the second best in the common area close to the coast. However, the temporal coverage for this last radial decreases drastically in the vicinity of the 
islands and peninsula due to the masking effect of land. A similar but weaker loss of temporal coverage is observed with the POR-BEN radial in the region where the bistatic travel paths are masked by Porquerolles Island. The region south of the islands is also poorly covered by PEY-BEN except for an isolated spot corresponding to the red circle in Figure 7 where a free way can be found between the Port-Cros and Levant islands.

Incomplete time coverage can result in a significant bias in the mean elliptical velocity. This is a consequence of the non uniform distribution of SNR with respect to the values of elliptical velocity as can be observed experimentally, if not yet theoretically explained. We have indeed observed on long series of data that larger magnitude of elliptical velocity are in general associated to smaller values of SNR. Hence, when thresholding the PSD with a given SNR, the proportion between the populations of "small" and "large" currents is modified in favor of the former. This induces a negative bias for the mean magnitude of currents.

This biasing effect of insufficient temporal coverage accounts for the anomalous drop of level which is observed for the mean PEY-PEY radial (contour 2B in Figure 6). It also explains the strong impa ct of the sporadic Radio-Frequency Interferences (RFI) which deteriorate the mean current in spite of their rare occurrence and cause strong outliers at the lower and eastern ends of the radar coverage: contours 3C, 3D for the mean POR-PEY elliptical velocity; contours $2 \mathrm{C}$ for the PEY-PEY radial.

However, as we will see, the acknowledged limitations of the radials in specific regions can be mitigated by a simultaneous use of all available radials. For example, the blue contours in the western part of t he POR-PEY (4A) and PEY-BEN (3B) elliptical velocity maps indicate a region where the poor quality of the PEY-PEY radial can be compensated and the easternmost blue contour (4D) on the PORPEY elliptical velocity map is a favorable correction to the near-range bistatic artifact of the POR-BEN elliptical velocity in the vicinity of Porquerolles Island.

\subsection{GDOP improvement}

(a)

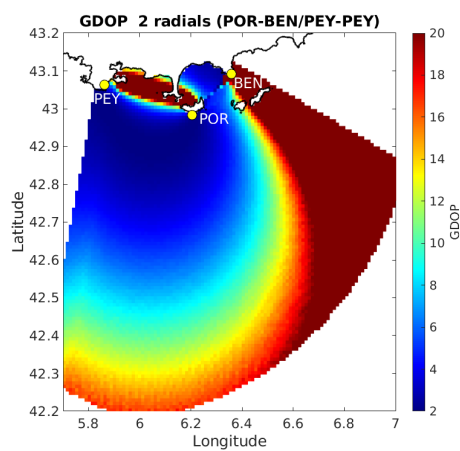

(b)

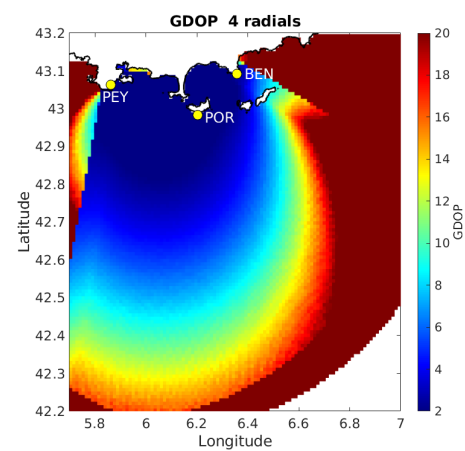

Fig. 8- GDOP of the vector reconstruction with a) two primary radials; $b$ ) the four available radials. The GDOP is mainly improved in the eastern part of the radar coverage. 
The reconstruction of the surface current vector $\boldsymbol{U}$ in the case of more than two available projections can be performed using a standard unweighted leastsquare fitting procedure (Lipa and Barrick (1983)). Denoting $\boldsymbol{U}_{n}=\left(U_{n_{1}}, . ., U_{n_{p}}\right)$ the $p$ available projections of $\boldsymbol{U}$ within some search radius around a grid point, a projection matrix $G$ is defined as

$$
G=\left(\begin{array}{l}
\cos \theta_{1} \sin \theta_{1} \\
\cdots \\
\cos \theta_{p} \sin \theta_{p}
\end{array}\right)
$$

where $\theta_{i}$ is the direction (measured counterclockwise from East) of the $i t h$ projection at the grid point, that is the direction of the outwards normal to the ellipse defined by the chosen pair of transmitter and receiver. The least-square solution $\boldsymbol{U}=\left(U_{n}, U_{e}\right)$ for the northward and eastward components of the surface current is then given by:

$$
\boldsymbol{U}=\left(G^{T} G\right)^{-1} G^{T} \boldsymbol{U}_{n}
$$

Note that several radials originating from the same bistatic pair can fall within the radius of research around a given grid point, in which case they are averaged. Hence, the number of surface current projections $p$ will always lie between 2 and 4 , according to the number of admissible bistatic pairs on a grid point. As it is well known, the quality of the surface current vector reconstruction from its projected components is constrained not only by the accuracy of the radials themselves but also by the angle between the two directions of projection. This last limitation, which is purely geometrical, is quantified by the so-called Geometric Dilution Of Precision (GDOP, Chapman et al (1997); Kim et al (2008)). The GDOP factor for the northward and eastward components is given by:

$$
\begin{aligned}
& \alpha_{n}=\operatorname{Det}\left(\left(G^{T} G\right)^{-1}\right) \sum_{i=1}^{L} \sin ^{2} \theta_{i} \\
& \alpha_{e}=\operatorname{Det}\left(\left(G^{T} G\right)^{-1}\right) \sum_{i=1}^{L} \cos ^{2} \theta_{i}
\end{aligned}
$$

Assuming equal variance error $\sigma^{2}$ on the elliptical velocities, this results in:

$$
\sigma_{n}^{2}=\alpha_{n} \sigma^{2}, \sigma_{e}^{2}=\alpha_{e} \sigma^{2}, \sigma_{n e}^{2}=\left(\alpha_{n}+\alpha_{e}\right) \sigma^{2}
$$

for the variance errors of the northward, eastward and total current, respectively.

Figure 8 shows the GDOP for the total current according to whether it is obtained with the two primary radials (a) or the four available radials (b). As seen, the introduction of the secondary radials (b) significantly improves the GDOP in the eastern part of the radar coverage, south off the islands. Another noticable correction is seen in the near-range between Fort Peyras and Porquerolles Island but cannot be exploited since this region is prohibited by the geometrical bistatic artifacts. 
(a)

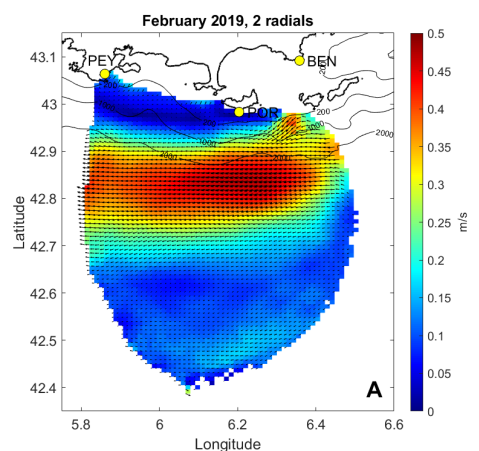

(c)

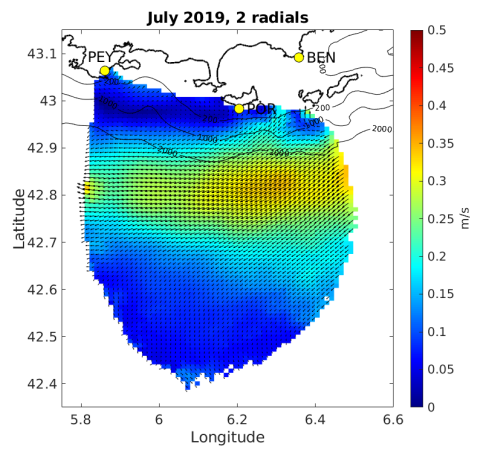

(b)

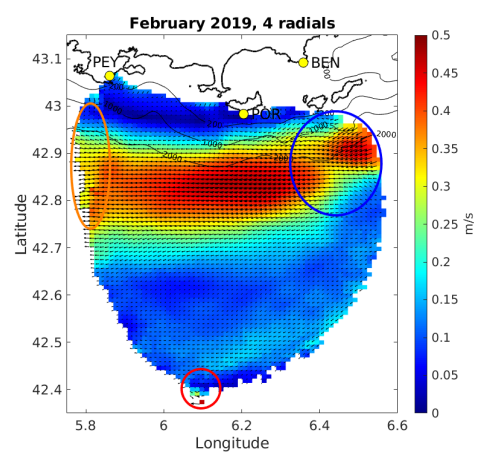

(d)

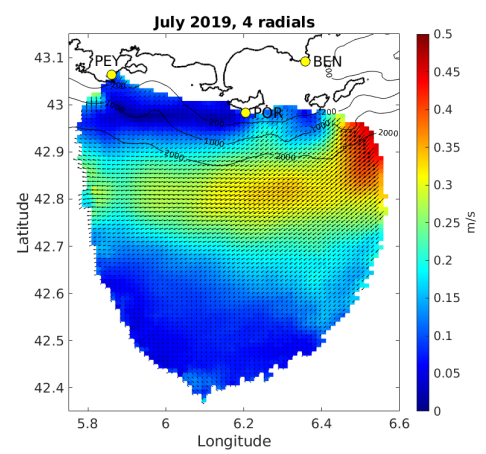

Fig. 9 - Monthly surface current reconstruction $(1 \mathrm{~km} \times 1 \mathrm{~km}$ grid cell) using a) and c): two primary radials; $b$ ) and $d)$ : at least two of the four elliptical velocities. The same maximal GDOP $(=8)$ has been imposed and the radials have been averaged over the month before the reconstruction. The use of the secondary radials improve both the coverage and the quality of the reconstruction. However, the observed non-physical bottlenecks on both ends of the main $N C$ vein are either not corrected (orange ellipse) or only partially corrected (blue ellipse). A small contamination by RFI is also seen at the lower end of the domain (red circle).

\section{Performances of the multistatic reconstruction}

The joint analysis of the SNR and GDOP indicate that the primary radials (PEY-PEY/POR-BEN) are the most appropriate for deriving the vector surface current on the largest area. The reconstruction is performed as described above on a $1 \mathrm{~km} \times 1 \mathrm{~km}$ Cartesian grid cell using a search radius of $2 \mathrm{~km}$ where only radial pairs with a mutual angle between 30 and 150 degrees (corresponding to a $\mathrm{GDOP} \leq 8$ ) have been retained. Examples of monthly averaged reconstructions are shown in the left panels of Figure 9 for the months of February 2019 and July 2019. The dominant NC vein is well described in the central part of the radar coverage and is more intense during the winter period. Its nonphysical reduction and truncation at both ends of the domain is, again, a consequence of the geometrical artifacts and the limited temporal coverage of the primary radials. However, as anticipated while discussing the merits of the respective radials, the use of the secondary radials makes it possible to improve both the coverage and the quality of the reconstruction in some regions. This is shown in the right panels of Figures 9, 
where the same reconstruction are performed using at least 2 available projections (and at most 4) within the full set of available elliptical velocities. Prescribing the same maximal value of GDOP $(=8)$, the spatial coverage (defined by a SNR larger than $5 \mathrm{~dB}$ for at least 2 simultaneous radials) is significantly extended to the easternmost part of the domain and the bistatic artifacts of the primary radials in the near-range ellipses are mitigated (blue circle in Figures 9). An extension of the coverage is also observed in the western region south of Fort Peyras where the PEY-PEY primary radial is deficient (orange circle). However, the correction due to the addition of 2 extra elliptical velocities in the original western coverage is less pronounced. This is related to the value of the GDOP, which is hardly decreased in this region by the addition of the extra radials (see Figure 8). Even though the addition of the secondary radials is useful to complement the primary radials in the eastern part of the radar coverage, the vector reconstruction of the mean current in this region is still not fully satisfactory. A non-physical discontinuity in shape and magnitude of the $\mathrm{NC}$ vein of current is still visible, although attenuated (blue circle in Figures 9). A spot of higher intensity results from the introduction of the secondary radials and can be related to the same spot seen for the time coverage of the PEY-BEN elliptical velocity (blue circle in the PEY-BEN map of Figure 7 ). Indeed as explained earlier, a significant reduction of the temporal coverage induces a negative bias for the mean current magnitude; conversely, any spot of high coverage with respect to the background (here, about $80 \%$ versus $40 \%$ ) will appear as a spot of more intense currents by contrast with the background.

Another benefit from a redundant, multistatic observation is the robustness of the reconstruction with respect to hardware failures. The surface current vector can still be reconstructed, even with a degraded quality and reduced spatial coverage if one transmitter or one receiver is not working. This is shown in Figure 12 which synthesizes the case study of February 20, 2019 with the reconstruction of the average current over the Tethys cruise period (8:00-20:00 UTC). The upper left panel shows the standard configuration with the two primary radials, the upper right panel shows the improved reconstruction with at least 2 radials among 4 available. The bottom panels shows a non-optimal reconstruction using a secondary radial, corresponding to the case where the Porquerolles or Peyras transmitter would be out of service. A common maximum GDOP threshold has been set to 10 in each configuration. As expected, the non-optimal reconstruction with the secondary elliptical velocities leads to a reduced coverage. However, the obtained surface current maps are perfectly consistent in magnitude and location with the standard primary reconstructions and are able to capture the main structures of the surface current on this day, that is the core of the $\mathrm{NC}$ vein and the onshore eddy in the vicinity of Fort Peyras.

The multistatic reconstruction can also be used to quantify the absolute errors in the surface current estimation, at least for time-averaged surface currents. Assuming that the estimation errors for the elliptical velocities pertaining to different transmitters or receivers are uncorrelated, one can compare each measured elliptical velocity $U_{r}$ obtained with, say transmitter $T X_{1}$ and receiver $R X_{1}$, with the backprojection $\tilde{U}_{r}$ of the reconstructed current vector estimated using a pair of transmitter/receiver $\left(T X_{2}, R X_{1}\right)$ or $\left(T X_{1}, R X_{2}\right)$. We found an overall RMSD of $3.48 \mathrm{~cm} / \mathrm{s}$ and $2.53 \mathrm{~cm} / \mathrm{s}$, respectively, between the POR-PEY and PEY-BEN radials and their backprojections, showing an excellent global consistency and accuracy of the different elliptical velocities. 


\section{Comparisons with surface drifters}
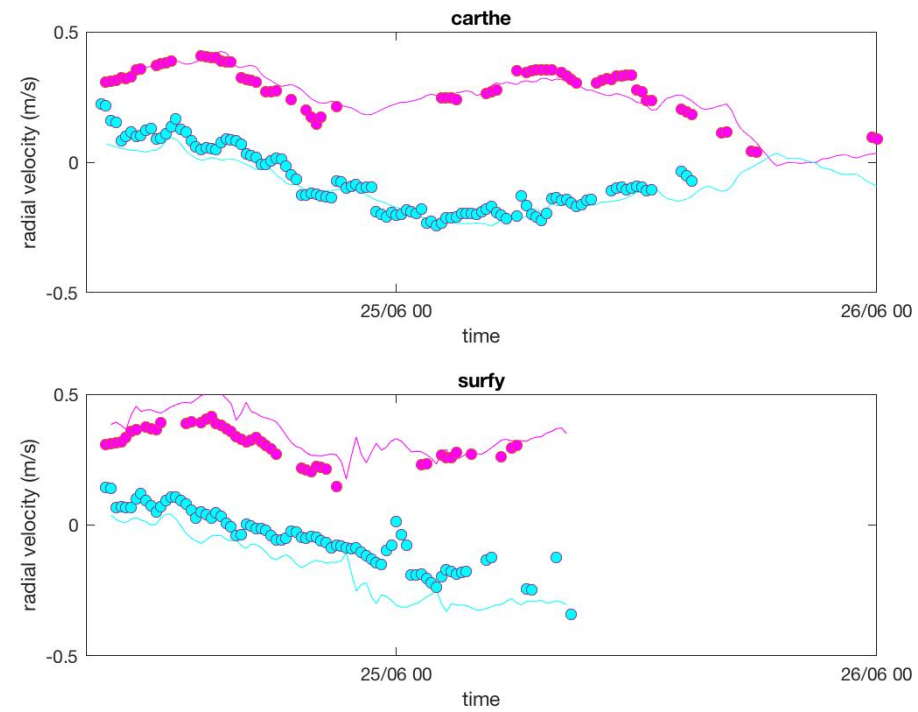

Fig. 10 - Time evolution of the radial velocity for the drifter (line) and for the radar station (circles), for PEY-PEY (magenta) and POR-BEN (cyan) stations of Launch 3. The upper panel represents the carthe comparison, the lower panel the surfy one.

The comparison between drifter types and HFR was done by interpolating the drifter positions on a regular time vector (15 minutes) to filter possible spikes, computing the drifter velocity by centered finite differences method, and projecting the velocity vector on the HFR radial direction, for each station. The HFR radial velocities are temporally interpolated on the same regular time vector, and the value in the radar cell closest to the drifter position is compared with the drifter inferred radial-equivalent velocity. Due to the small number of drifters, the choice was made to do single drifters comparison instead of averaging all the available drifters velocities among the radar cell. Note that due to the navigational limitations, the drifters were not dropped further than $42.85 \mathrm{deg} \mathrm{N}$ and experienced mostly a westward journey. When comparing the drifter trajectories with the radial maps (Figure 5) it is obvious that we are at the limit of coverage for most of the radials, in particular for the secondary ones.

To evaluate the impact of the drifter type, only the third launch is plotted on Figure 10, as the time evolution of the radial velocity for the drifter and for the radar station. The primary radials PEY-PEY and POR-BEN have been selected as they are the most reliable. The HFR radial velocities compared very well with the carthe-type drifter, while the surfy-type drifter velocity experienced a larger velocity of about $10 \mathrm{~cm} / \mathrm{s}$. This is coherent with Stewart and Joy (1974) who showed that, for a linear surface current vertical profile, the effective measurement depth is given by $d_{\text {eff }}=\lambda_{\text {radar }} / 8 \pi$. Using this relation, the effective depths of the 

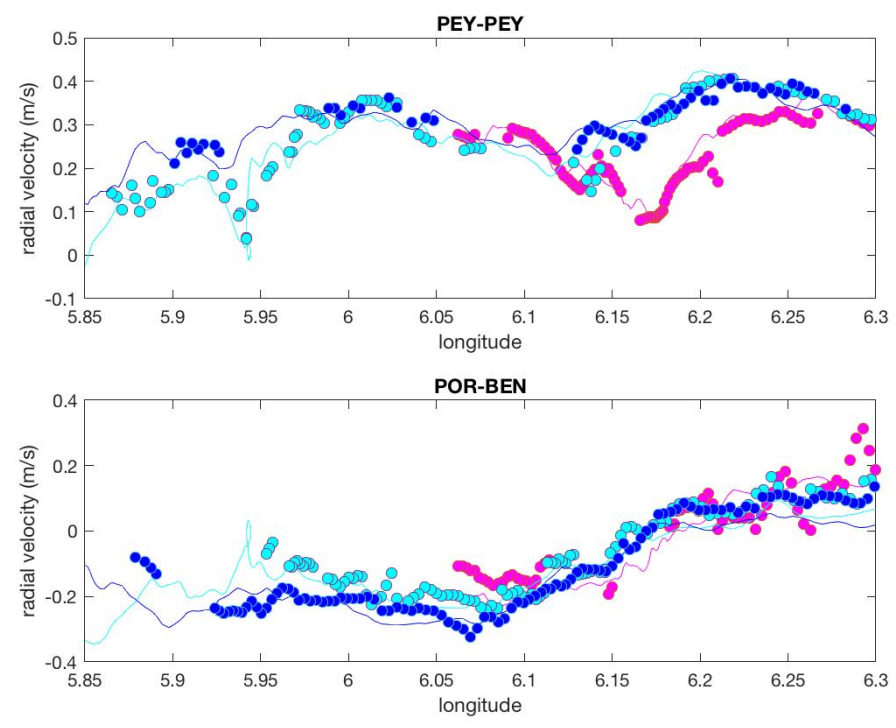

FIG. 11 - Radial velocity as a function of longitude measured by the carthe drifters (line) and by the radar stations (circles). Only the 3 longest trajectories are plotted: L2 in magenta, $L 3$ in cyan and L4 in blue. The upper panel represents the PEY-PEY radial, the lower panel the POR-BEN radial.

current measurements are estimated to be $0.65 \mathrm{~m}$ for the $16.15 \mathrm{MHz}$ range system, which is the theoretical depth of the vertically averaged velocity calculated from the successive drifter displacement for the carthe design. Based on these results, we can assert that the carthe drifters are the ones that best compare with HFR, because of their design reducing the Stokes drift and the windage, and measuring an integrated surface velocity almost equivalent to the radar-inferred one. Figure 11 depicts the elliptical velocities as a function of longitude (since the displacements is mostly westward) for the longest carthe drifters trajectories (L2, L3, L4) and for the two primary radials (POR-BEN and PEY-PEY). The hourly radial velocities from the radar and the drifter are very consistent, in terms of magnitude and variability. Focusing on the carthe drifters only, the overall statistics in terms of RMSD and correlation between velocities measured by the HFR and by the drifters are listed in Table 1 , for the 5 launches and the 4 radial maps. Note that the HFR radial velocity fields were not filtered, and may present some missing data in time and/or space, in addition to radio interferences. We set some arbitrary minimal and maximal thresholds for the statistical parameters, beyond which the value is considered to be very good (highlighted in blue in Table 1) or very bad (highlighted in red). These threshold values are $5 \mathrm{~cm} / \mathrm{s}$ and $10 \mathrm{~cm} / \mathrm{s}$ for the RMSD of current, 0.8 and 0.5 for the correlation coefficient and $1 \mathrm{~cm} / \mathrm{s}$ and $5 \mathrm{~cm} / \mathrm{s}$ for the bias of current. The RMSD can be very variable. The high RMSD of L1-POR-BEN , and to some extent of L2, can probably be explained by the position of the drifters too close to the first ellipse of the radial. Outside of these values, e.g. away from the radial map edges, the RMSD for the primary radials range from 2.3 to $5 \mathrm{~cm} / \mathrm{s}$, which is a very satisfying result. As expected the PEY-PEY radial gives the best results, considering that 


\begin{tabular}{|c|c|c|c|c|c|c|c|}
\hline Elliptical velocities & & L1 & $\mathrm{L} 2$ & L3 & L4 & L5 & ALL \\
\hline \multirow[t]{3}{*}{ PEY-PEY } & RMSD & 0.052 & 0.029 & 0.044 & 0.026 & 0.024 & 0.035 \\
\hline & corr & 0.75 & 0.94 & 0.90 & 0.87 & 0.86 & 0.93 \\
\hline & bias & 0.051 & 0.011 & 0.000 & 0.000 & 0.003 & 0.005 \\
\hline \multirow[t]{3}{*}{ POR-BEN } & RMSD & 0.178 & 0.072 & 0.046 & 0.050 & 0.033 & 0.068 \\
\hline & corr & 0.38 & 0.89 & 0.96 & 0.95 & 0.21 & 0.89 \\
\hline & bias & 0.144 & -0.022 & -0.029 & -0.017 & -0.030 & -0.013 \\
\hline \multirow[t]{3}{*}{ PEY-BEN } & RMSD & 0.041 & 0.030 & 0.109 & 0.163 & 0.023 & 0.132 \\
\hline & corr & 0.35 & 0.34 & 0.43 & 0.07 & 0.79 & 0.19 \\
\hline & bias & 0.030 & -0.001 & 0.035 & -0.060 & -0.012 & -0.025 \\
\hline \multirow[t]{3}{*}{ POR-PEY } & RMSD & 0.056 & 0.062 & 0.105 & 0.061 & 0.028 & 0.072 \\
\hline & corr & 0.49 & 0.24 & 0.60 & 0.06 & 0.80 & 0.41 \\
\hline & bias & 0.037 & 0.051 & 0.068 & 0.021 & 0.021 & 0.041 \\
\hline \multicolumn{8}{|l|}{ Total velocities } \\
\hline \multirow[t]{3}{*}{$\mathrm{V}$} & RMSD & 0.158 & 0.055 & 0.052 & 0.055 & 0.042 & 0.066 \\
\hline & corr & -0.07 & 0.74 & 0.85 & 0.63 & 0.93 & 0.61 \\
\hline & bias & 0.138 & -0.028 & -0.033 & -0.007 & -0.038 & -0.012 \\
\hline \multirow[t]{3}{*}{$\bar{U}$} & RMSD & 0.078 & 0.040 & 0.043 & 0.044 & 0.037 & 0.045 \\
\hline & corr & 0.51 & 0.95 & 0.96 & 0.82 & 0.68 & 0.90 \\
\hline & bias & 0.052 & -0.030 & -0.034 & -0.017 & -0.027 & -0.021 \\
\hline \multirow[t]{3}{*}{ speed } & RMSD & 0.027 & 0.030 & 0.039 & 0.041 & 0.035 & 0.037 \\
\hline & corr & 0.68 & 0.94 & 0.84 & 0.75 & 0.74 & 0.91 \\
\hline & bias & 0.002 & 0.012 & 0.014 & 0.013 & 0.026 & 0.013 \\
\hline
\end{tabular}

TАв. $1-R M S D$, bias (in $\mathrm{m} / \mathrm{s}$ ) and correlation coefficient between radial velocities from the $H F R$ and from the drifters for each launch and for each radial. Total velocities ( $U, V$, speed) are computed from the primary radials and compared with the drifters velocities. Highlighted cells indicate very good (blue) or very bad (red) statistical values.

almost all the drifters, except for the first one L1, remain within radar coverage and high SNR (Figure 7). The RMSD of primary radials are found significantly improved with respect to a former drifter-radar comparison using the same HFR network (Sentchev et al (2017), where these RMSD were found to be $6 \mathrm{~cm} / \mathrm{s}$ and $8 \mathrm{~cm} / \mathrm{s}$ for the PEY-PEY and POR-BEN elliptical velocities, respectively. This is very likely due to the aforementioned upgrades in the hardware radar system and processing algorithms as well as an increased range resolution (from $3 \mathrm{~km}$ to 1.5 $\mathrm{km})$. The L5 drifter stopped transmitting after only a few hours, and data may not be reliable. L1 and L5 and the corresponding short trajectories are at least responsible for the relatively low correlation values, which otherwise reach values of the order of 0.9 . The table 1 shows large discrepancies between different releases when considering the secondary radials. The RMSD ranges from good (from 2.3 to 6.1) for L1,L2 and L5 (but with highly variable correlations), to acceptable for all but L4-PEY-BEN, probably due to a local and temporary interference in the radar signal. As to the components of the total currents, the zonal component is found of much better quality that the meridional one with an overall RMSD smaller than $5 \mathrm{~cm} / \mathrm{s}$, a correlation of 0.9 and a bias of $-2 \mathrm{~cm} / \mathrm{s}$. This difference can be attributed to the smaller values of the meridional components which increase the relative errors. Overall, considering the limited number of drifters, the navigational limitations and the use of raw radial data (no filtering or smoothing) the results are very encouraging compared to previous studies. For example, Ohlmann and et. al (2007) compares HF radar-derived velocities (radials and totals) with velocity estimates from averaging large numbers of simultaneous drifter observations and report an overall RMSD in radial velocities of $6.5 \mathrm{~cm} / \mathrm{s}$, and a correlation coefficient 
of 0.84. Kirincich et al (2019) uses Coastal Dynamics Experiment (CODE)-style (Davis (1985)) surface drifters with a maximum drogue depth of $1 \mathrm{~m}$, to validate a DF algorithm tested on a generic HFR installed over the New England shelf and obtains a RMSD range from 5 to $10 \mathrm{~cm} / \mathrm{s}$ (up to $20 \mathrm{~cm} / \mathrm{s}$ ) and correlation between 0.46 and 0.73 . Kalampokis et al (2016) compares velocities from a CODAR HFR and CODE-design drifters (in the Gulf of Naples), and obtain a RMSD of 5 $\mathrm{cm} / \mathrm{s}$ and a correlation coefficient 0.8-0.85. In Bellomo et al (2015), different HFR experiments along the Mediterranean coast are studied, and radial velocities are compared to CODE- drifters. The RMSD ranges from 4.7 to $9.6 \mathrm{~cm} / \mathrm{s}$.

\section{Comparison with ADCP}

(a)

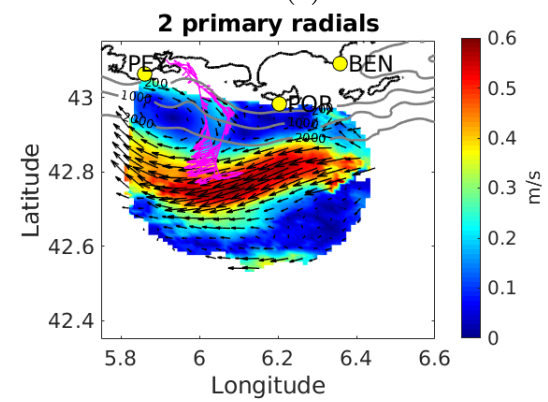

(c)

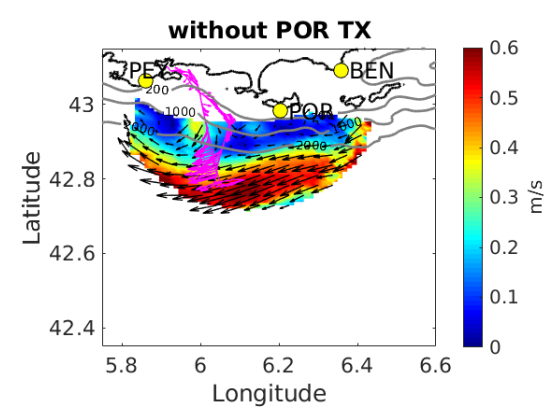

(b)

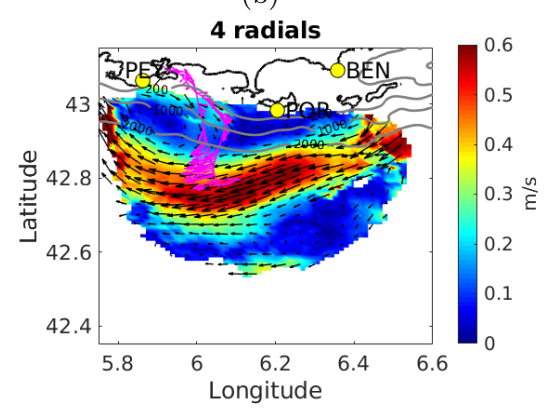

(d)

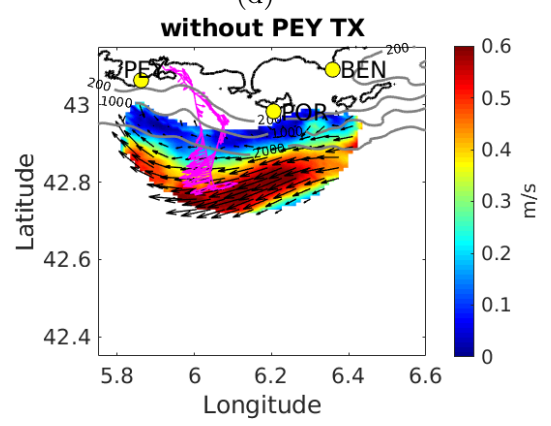

FIG. 12 - Surface current observed over 10 hours during the Tethys-2 sea trip on February 20, 2019, 8:00-18:00 UTC. The vector field is obtained from a reconstruction using a) 2 primary radials; b) at least 2 of the 4 available elliptical velocities; $c$ ) the non-optimal combination of radials PEY-PEY/PEY-BEN corresponding to a failure of the Porquerolles transmitter; d) the non-optimal combination of radials POR-BEN/POR-PEY, corresponding to a failure of the Peyras transmitter. The magenta arrows show the instantaneous current vector measured by the ADCP along the ship transect.

The HFR velocities mapped in Figure 12 show a shift of the NC vein from the 1000-2000 isobaths between $5.9 \mathrm{deg}$ E and $6.1 \mathrm{deg}$ E, with a maximum southward extend of $10 \mathrm{~km}$ offshore the $2000 \mathrm{~m}$ isobath. Between the meander trough and the coast, the HFR velocities reveal an anticyclonic eddy about 15-17 km in diameter 
(a)

(b)

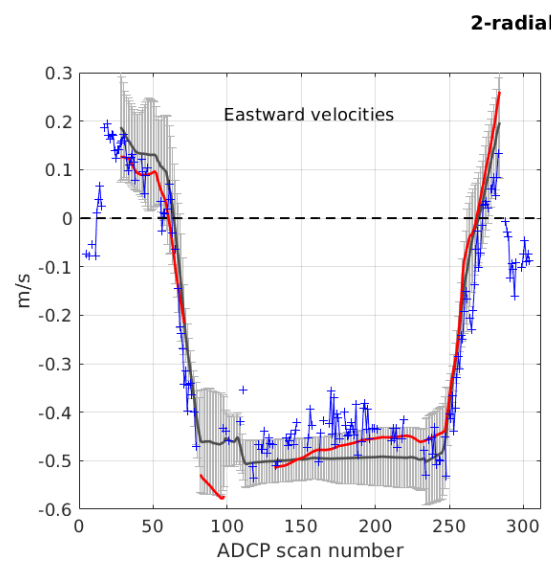

(c)

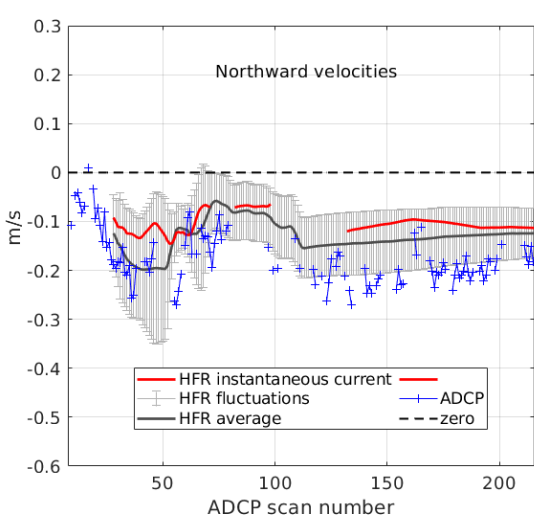

(d)

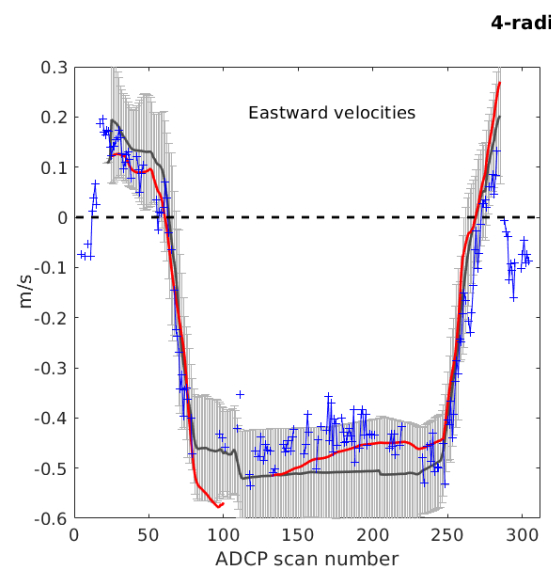

4-radials estimates

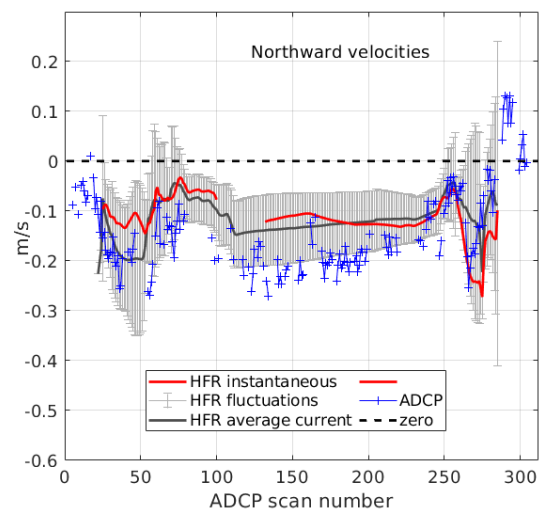

FIG. 13 - Comparison of the zonal and meridional component of the ADCP (16.47 $\mathrm{m}$ depth bin) and instantaneous HFR currents along the ship transect when the reconstruction is performed with: a) and b) 2 primary elliptical radials; c) and d) at least 2 of the 4 elliptical radials. The black solid line is the time average of the HFR currents over the cruise period (10 hours) and the gray error bars are the fluctuations around this mean value ( \pm 2 standard deviations)

that is closely of same dimension than the meander pseudo-wavelength (ca 0.2 degree of longitude or $16 \mathrm{~km}$ ). The meander entered the HF radar area ${ }^{4}$ on February 17, 2019 and leaved on February 22, 2019, hence lasting 5 days with a mean phase velocity of ca $10 \mathrm{~cm} / \mathrm{s}(8-9 \mathrm{~km} /$ day $)$ as often observed in previous field or modeling

4. see http://hfradar.univ-tln.fr/HFRADAR/ 


\begin{tabular}{|c|c|c|c|c|}
\hline & 2 radials & & 4 radials & \\
\hline & exact time & time averaged & exact time & time averaged \\
\hline U & & & & \\
\hline RMSD & 0.068 & 0.065 & 0.068 & 0.069 \\
corr & 0.968 & 0.977 & 0.966 & 0.977 \\
bias & -0.014 & -0.005 & -0.014 & 0.003 \\
\hline V & & & & 0.082 \\
\hline RMSD & 0.083 & 0.063 & 0.087 & 0.484 \\
corr & 0.045 & 0.634 & 0.147 & -0.046 \\
bias & -0.044 & -0.041 & -0.043 & 0.063 \\
\hline speed & & & & 0.928 \\
RMSD & 0.066 & 0.058 & 0.886 & -0.002 \\
corr & 0.906 & 0.932 & 0.016 & \\
bias & 0.014 & 0.004 & \multicolumn{3}{|c}{} \\
\hline
\end{tabular}

TAв. 2 - RMSD (in $\mathrm{m} / \mathrm{s}$ ), correlation coefficient and bias (mean difference, in $\mathrm{m} / \mathrm{s}$ ) between HFR velocities and VM-ADCP data for the 2 primary radials (left columns) or using at least 2 of the 4 available radials (right columns). In each case, the statistics are given for the exactly space and time colocated velocities and the time averaged and space colocated ones.

studies (e.g. Crépon and Richez (1982); Sammari et al (1995)). Such a situation is frequent in the studied area, the NC being known to be a topographically guided geostrophic current; it follows closely the 1,000-2,000-m isobaths but is subject to baroclinic and barotropic instabilities, particularly in winter time, leading to the frequent generation of meanders of some tens $\mathrm{km}$ in amplitude and wavelength propagating westward along its main path (e.g. Crépon and Richez (1982); Taupier-Letage and Millot (1986); Alberola et al (1995); Sammari et al (1995); Flexas et al (2004); Casella et al (2011); Guihou et al (2013)). Nevertheless, the eddy mean diameter and meander's amplitude and pseudo-wavelength are about the order of the Rossby radius of deformation $(10-15 \mathrm{~km}$ in the Northwestern Mediterranean Sea), hence in the very lower range of previous observations of the NC meander and associated eddies upstream the studied area (e.g. Millot (1991); Casella et al (2011); Guihou et al (2013); Piterbarg et al (2014)).

Even if the ship path does not entirely cross this mesoscale mixed structure, the ADCP velocities reversals nearshore are consistent with an anticyclonic eddy pattern on the vessel round-trip, as well as the net increase and westward alignment of ADCP velocities south of $42.9 \mathrm{deg} \mathrm{N}$ when approaching (forth trip) or leaving (back trip) the NC vein. To go deeper than this first qualitative validation, we compared both velocity estimates, with HFR ones being linearly interpolated over the path and time of the ADCP measurements (Figure 13). Despite the known reservations in comparing HFR and ADCP currents, Figure 13a shows that the two zonal velocity estimates are in good agreement, with very similar values onshore $(+0.15 \mathrm{~m} / \mathrm{s})$ that closely reverse offshore when approaching the $\mathrm{NC}$ vein and reach similar minimum values in the core of the current. Those are only slightly lower with the ADCP but always in the variability range of the HFR (-0.4 to -0.6 $\mathrm{m} / \mathrm{s})$. The Pearson correlation coefficient between both estimates is 0.97 and the root mean square difference and bias are $6.82 \mathrm{~cm} / \mathrm{s}$ and $-1.42 \mathrm{~cm} / \mathrm{s}$, respectively. By contrast, the comparison of meridional velocities is less convincing, with HFR velocities being systematically lower (bias $=-4.33 \mathrm{~cm} / \mathrm{s}$ ), a higher RMSD (8.33 $\mathrm{cm} / \mathrm{s})$ and a quasi-null correlation $(\mathrm{R}=0.045)$. The ADCP estimates are, however, generally close to or inside the variability range of HFR and the onshore-offshore trends quite similar, and even very close in the last part of the ship trip. A bet- 
ter correlation between HFR and ADCP for the major component of the current (here the zonal velocity due to the mean westward orientation of the NC) has been yet observed in previous assessment studies (e.g. Paduan and Rosenfeld (1996); Kelly et al (2002); Robinson et al (2011)). The more likely explanation is that the minor component is more subject to short term or small space-scale variability, as Ekman induced vertical gradient and direction veering, hence relatively more marked discrepancies with the ADCP data. In our case, using the ship time averaged HFR velocities instead of the path and exact time interpolated helped smoothing this higher relative variability of the minor component and greatly improved the statistics with a higher correlation coefficient $(\mathrm{R}=0.64)$ and lower RMSD (6.23 $\mathrm{cm} / \mathrm{s}$, respectively). Note that using the time averaged HFR velocity fields also fills hourly holes of the raw data (as seen by the interruption of the space end time extracted series on Figure 13) in the extracted series, leading to more values available for the statistics. Finally, except for the exactly extracted meridional component, the RMSD and bias between both estimates are no more that 2-3 times the typical measurements errors of each instruments, that are about 2.5-3.5 $\mathrm{cm} / \mathrm{s}$ for the HFR (see section 4) and ca $2-4 \mathrm{~cm} / \mathrm{s}$ for the VM-ADCP. That seems reasonable given the fact that the low frequency $(75 \mathrm{kHz})$ of the Tethys- 2 mounted ADCP is far to be adapted for a best assessment of HFR surface velocities.

This first qualitative and quantitative analysis hence gives us robust arguments about the capacity of our HFR standard configuration with only the two primary radials to catch meso to submesoscale patterns. The question is now to assess the alternate configurations, i.e. the more complete one with all available radials (primary and secondary ones) and the degraded configurations. Results obtained with all available radials are shown in the bottom panel of Figure 13 with their statistics of ADCP comparisons summarized in Table 2. As expected, the velocity fields reconstructed with all available radials gives very similar results than the standard two primary radials ones: the space scales of the currents' structure are conserved with the same current intensity, both for the NC vein and the eddy. The statistics (correlation coefficients, RMSD and bias), are similarly good for the zonal component and only slightly improved for the meridional one. The main difference is the better upstream resolution of the $\mathrm{NC}$ vein East of $6.3 \mathrm{E}$, as previously shown in Section 4, that allows to correct the doubtful sudden apparition of the NC vein seen in the standard two primary radials configuration. This improvement is critical as the NC is known to flow continuously along the coast from the Ligurian Sea to the Catalan Sea. 


\section{Conclusions}

The HFR network in Toulon is an original multistatic configuration to monitor the surface current, with 2 separated transmitters and receivers on 3 distant sites. The specificity of the bistatic geometry have been discussed and the limitations of the various elliptical velocities have been underlined: near-range variations of the bistatic angle, land masking, orientation of antenna arrays, SNR. Some pitfalls have been identified when processing mean currents, such as a negative bias on magnitude and strong RFI outliers in the case of an incomplete temporal coverage. Among the four available combinations leading to elliptical projections of the surface current vector, only 2 have been identified as primary, in the sense that they provide the best quality reconstruction and the wider coverage. Nevertheless, the secondary radials have been shown to extend the coverage and improve the reconstruction in some specific areas where the primary radials have identified defects. They have also be seen to be a useful substitute in case of hardware failure. We also found that having more than 2 independent elliptical projections of the surface current makes it possible to estimate their absolute accuracy thanks to a technique of reconstruction and reprojection. The measured hourly radials have been assessed though 2 types of oceanographic in situ measurements. A 2day dedicated drifter campaign with 5 launches was analyzed and compared with instantaneous HFR surface currents. An overall good quantitative agreement has been found with the carthe drifters which integrate the current over the $65 \mathrm{~cm}$ top layer, with a RMSD of at most $7 \mathrm{~cm} / \mathrm{s}$ for the primary radials and $13 \mathrm{~cm} / \mathrm{s}$ for the secondary radials. When focusing on some trajectories that have the largest intersection with the radar coverage, an excellent agreement is obtained with RMSD of the order of $2.5 \mathrm{~cm} / \mathrm{s}$ and $3-5 \mathrm{~cm} / \mathrm{s}$, respectively for the primary radials. Opportunity ADCP data from a 12 hours cruise on February 20, 2019 inside the radar coverage showed a good qualitative agreement with HFR derived currents and the ability of the latter to catch the spatio-temporal variability of the main meso-scale structures. For both the ADCP and drifter comparison, it has been found that the estimation of the dominant component of the current (zonal) is more reliable than the meridional one, which is significantly smaller and more subject to small-scale fluctuations.

Acknowledgements The upgrade of the WERA HFR system in Toulon as well as one of the authors (Anthony Gramoullé) have been funded by the EU Interreg Marittimo program SICOMAR-PLUS; the drifters have been acquired in the framework of the EU Interreg Marittimo program IMPACT; the operational maintenance of the installations has been contracted to the Degréane Horizon company over the period 2019-2021. We acknowledge the University of Toulon and the Ministère de l'Enseignement Supérieur, de la Recherche et de l'Innovation for funding the first author. The long-term monitoring of the Northern Current is part of the Mediterranean Ocean Observation Service for the Environment (MOOSE). We thank the Parc National de Port-Cros (PNPC) for its support and hosting of our radar transmitter in Porquerolles Island. We also thank the "Association Syndicale des Propriétaires du Cap Bénat" (ASPCB) for allowing our receiver array at the Cap Bénat as well as the Group Military Conservation and the Marine Nationale for hosting our radar installation in Fort Peyras. 


\section{Références}

Alberola C, Millot C, Font J (1995) On the seasonal and mesoscale variabilities of the northern current during the primo-0 experiment in the western mediterranean-sea. Oceanologica Acta 18(2):163-192

Ardhuin F, Marié L, Rascle N, Forget P, Roland A (2009) Observation and estimation of lagrangian, stokes, and eulerian currents induced by wind and waves at the sea surface. Journal of Physical Oceanography 39(11):2820-2838

Barrick D (1972a) Remote sensing of sea state by radar. Remote sensing of the troposphere $12: 1-46$

Barrick DE (1972b) First-order theory and analysis of MF/HF/VHF scatter from the sea. Antennas and Propagation, IEEE Transactions on 20(1):2-10

Baskin C, Roarty H, Kohut J, Glenn S (2016) Effectiveness of a bistatic system on high frequency radar resiliency. In: OCEANS 2016 MTS/IEEE Monterey, pp 1-5, DOI 10.1109/OCEANS.2016.7761296

Bellomo L, Griffa A, Cosoli, Falco P, Gerin R, Iermano I, A K, Z K, Lana A, Magaldi M, Mamoutos I, Mantovani C, Marmain J, Potiris E, Sayol J, Barbin Y, Berta M, Borghini M, Bussani A, Corgnati L, Dagneaux Q, Gaggelli J, Guterman P, Mallarino D, Mazzoldi A, Molcard A, Orfila A, Poulain PM, Quentin C, Tintoré J, Uttieri M, Vetrano A, Zambianchi E, Zervakis V (2015) Toward an integrated HF radar network in the mediterranean sea to improve search and rescue and oil spill response: the TOSCA project experience. Journal of Operational Oceanography 8(2):95-107, DOI 10.1080/1755876X.2015.1087184

Capodici F, Cosoli S, Ciraolo G, Nasello C, Maltese A, Poulainc PM, Drago A, Azzopardi J, Gauci A (2019) Validation of HF radar sea surface currents in the malta-sicily channel. Remote Sensing of Environment 225:65-76, DOI 10.1016/j.rse.2019.02.026

Casella E, Molcard A, Provenzale A (2011) Mesoscale vortices in the ligurian sea and their effect on coastal upwelling processes. Journal of Marine Systems 88(1):12-19

Chapman R, Shay LK, Graber HC, Edson J, Karachintsev A, Trump C, Ross D (1997) On the accuracy of hf radar surface current measurements: Intercomparisons with ship-based sensors. Journal of Geophysical Research: Oceans 102(C8):18,737-18,748

Crépon M, Richez C (1982) Transient upwelling generated by two-dimensional atmospheric forcing and variability in the coastline. Journal of Physical Oceanography 12(12):14371457, DOI 10.1175/1520-0485(1982)012<1437:TUGBTD > 2.0.CO;2

Davis RE (1985) Drifter observations of coastal surface currents during code: The method and descriptive view. Journal of Geophysical Research: Oceans 90(C3):4741-4755

Declerck A, Ourmières Y, Molcard A (2016) Assessment of the coastal dynamics in a nested zoom and feedback on the boundary current: the north-western mediterranean sea case. Ocean Dynamics 66(11):1529-1542

Dumas D, Guérin CA (2020) Self-calibration and antenna grouping for bistatic oceanographic high-frequency radars. arXiv preprint arXiv:200510528

Enrile F, Besio G, Stocchino A, Magaldi M, Mantovani C, Cosoli S, Gerin R, Poulain PM (2018) Evaluation of surface lagrangian transport barriers in the gulf of trieste. Continental Shelf Research 167:125-138

Flexas M, Van Heijst G, Jordà G, Sánchez-Arcilla A (2004) Numerical simulation of barotropic jets over a sloping bottom: Comparison to a laboratory model of the northern current. Journal of Geophysical Research: Oceans 109(C12)

Forget P (2015) Noise properties of HF radar measurement of ocean surface currents. Radio Science 50(8):764-777

Graber HC, Haus BK, Chapman RD, Shay LK (1997) Hf radar comparisons with moored estimates of current speed and direction: Expected differences and implications. Journal of Geophysical Research: Oceans 102(C8):18,749-18,766

Grosdidier S, Forget P, Barbin Y, Guérin CA (2014) HF bistatic ocean Doppler spectra: Simulation versus experimentation. IEEE Trans Geosci and Remote Sens 52(4):2138-2148

Guérin CA, Dumas D, Gramoullé A, Quentin C, Saillard M, Molcard A (2019) The multistatic HF radar network in Toulon. In: IEEE Radar 2019 Conference, IEEE

Guihou K, Marmain J, Ourmieres Y, Molcard A, Zakardjian B, Forget P (2013) A case study of the mesoscale dynamics in the north-western mediterranean sea: a combined data-model approach. Ocean Dynamics 63(7):793-808 
Gurgel KW, Essen HH, Kingsley S (1999) High-frequency radars: physical limitations and recent developments. Coastal engineering 37(3):201-218

Kalampokis A, Uttieri M, Poulain PM, Zambianchi E (2016) Validation of HF radar-derived currents in the gulf of naples with lagrangian data. IEEE Geoscience and Remote Sensing Letters 13(10):1452-1456

Kelly F, Bonner J, Perez J, Adams J, Prouty D, Trujillo D, Weisberg RH, Luther ME, He R, Cole R, et al (2002) An hf-radar test deployment amidst an adcp array on the west florida shelf. In: OCEANS'02 MTS/IEEE, IEEE, vol 2, pp 692-698

Kim S, Terrill E, Cornuelle B (2008) Mapping surface currents from HF radar radial velocity measurements using optimal interpolation. Journal of Geophysical Research: Oceans $113(\mathrm{C} 10)$

Kirincich A, Emery B, Washburn L, Flament P (2019) Improving surface current resolution using direction finding algorithms for multiantenna high-frequency radars. Journal of Atmospheric and Oceanic Technology 36(10):1997-2014

Lefévre D (2010) Moose(antares). Tech. rep., CNRS-INSU, URL https://doi.org/10.18142/233

Lipa B, Barrick D (1983) Least-squares methods for the extraction of surface currents from codar crossed-loop data: Application at arsloe. IEEE Journal of Oceanic Engineering 8(4):226-253

Lipa B, Whelan C, Rector B, Nyden B (2009) Hf radar bistatic measurement of surface current velocities: drifter comparisons and radar consistency checks. Remote Sensing 1(4):11901211

Lumpkin R, Özgökmen T, Centurioni L (2017) Advances in the application of surface drifters. Annual Review of Marine Science 9:59-81

Marmain J, Forget P, Molcard A (2011) Characterization of ocean surface current properties from single site HF/VHF radar. Ocean Dynamics 61(11):1967-1979

Marmain J, Molcard A, Forget A, Barth A, Ourmières Y (2014) Assimilation of HF radar surface currents to optimize forcing in the northwestern Mediterranean sea. Nonlinear Processes in Geophysics 21(3):659-675

Millot C (1991) Mesoscale and seasonal variabilities of the circulation in the western mediterranean. Dynamics of Atmospheres and Oceans 15(3-5):179-214

Millot C, Taupier-Letage I (2005) Circulation in the Mediterranean sea. In: The Mediterranean Sea, Springer, pp 29-66

Molcard A, Poulain P, Forget P, Griffa A, Barbin Y, Gaggelli J, De Maistre J, Rixen M (2009) Comparison between VHF radar observations and data from drifter clusters in the Gulf of La Spezia (Mediterranean Sea). J Mar Syst 78:S79-S89, DOI https://doi.org/10.1016/j.jmarsys.2009.01.012

Morey S, Wienders N, Dukhovskoy D, Bourassa M (2018) Measurement characteristics of nearsurface currents from ultra-thin drifters, drogued drifters, and HF radar. Remote Sensing 10(10):1633

Novelli G, Guigand C, Cousin C, Ryan E, Laxage J, Dai H, Haus K, Özgökmen T (2017) A biodegradable surface drifter for ocean sampling on a massive scale. J Atmos Oceanic Technol 34:2509-2532, DOI 10.1175/JTECH-D-17-0055.1

Novelli G, Guigand C, Özgökmen T (2018) Technological advances in drifters for oil transport studies. Marine Technology Society Journal 52(6):53-61

Ohlmann C, et al (2007) Interpretation of coastal HF radar-derived surface currents with highresolution drifter data. Journal of Atmospheric and Oceanic Technology 24(4):666-680

Özgökmen T, Boufadel M, Carlson D, Cousin C, Guigand C, Haus B, Horstmann J, Lund B, Molemaker J, Novelli G (2018) Technological advances for ocean surface measurements by the consortium for advanced research on transport of hydrocarbons in the environment (carthe). Marine Technology Society Journal 52(6):71-76

Paduan JD, Rosenfeld LK (1996) Remotely sensed surface currents in monterey bay from shore-based hf radar (coastal ocean dynamics application radar). Journal of Geophysical Research: Oceans 101(C9):20,669-20,686

Paduan JD, Washburn L (2013) High-frequency radar observations of ocean surface currents. Annual review of marine science 5:115-136

Paduan JD, Kim KC, Cook MS, Chavez FP (2006) Calibration and validation of directionfinding high-frequency radar ocean surface current observations. IEEE Journal of Oceanic Engineering 31(4):862-875 
Piterbarg L, Taillandier V, Griffa A (2014) Investigating frontal variability from repeated glider transects in the ligurian current (north west mediterranean sea). Journal of Marine Systems 129:381-395

Quentin C, Barbin Y, Bellomo L, Forget P, Gagelli J, Grosdidier S, Guérin CA, Guihou K, Marmain J, Molcard A, Zakardjian B, Guterman P, Bernardet K (2013) HF radar in French Mediterranean Sea: an element of MOOSE Mediterranean Ocean Observing System on Environment. In: Ocean \& Coastal Observation: Sensors ans observing systems, numerical models \& information, Nice, France, pp 25-30, URL https://hal.archives-ouvertes.fr/hal00906439

Roarty H, Cook T, Hazard L, Harlan J, Cosoli S, Wyatt L, Alvarez Fanjul E, Terrill E, Otero M, Largier J, et al (2019) The global high frequency radar network. Frontiers in Marine Science 6:164

Robinson A, Wyatt L, Howarth M (2011) A two year comparison between hf radar and adcp current measurements in liverpool bay. Journal of operational oceanography 4(1):33-45

Röhrs J, Sperrevik AK, Christensen KH, Broström G, Breivik Ø (2015) Comparison of hf radar measurements with eulerian and lagrangian surface currents. Ocean Dynamics 65(5):679690

Rypina I, Kirincich A, Limeburner R, Udovydchenkov I (2014) Eulerian and lagrangian correspondence of high-frequency radar and surface drifter data: Effects of radar resolution and flow components. Journal of Atmospheric and Oceanic Technology 31:945-966, DOI 10.1175/JTECH-D-13-00146.1

Sammari C, Millot C, Prieur L (1995) Aspects of the seasonal and mesoscale variabilities of the northern current in the western mediterranean sea inferred from the prolig-2 and pros-6 experiments. Deep Sea Research Part I: Oceanographic Research Papers 42(6):893-917

Sentchev A, Forget P, Fraunié P (2017) Surface current dynamics under sea breeze conditions observed by simultaneous HF radar, adcp and drifter measurements. Ocean Dynamics 67(3-4):499-512

Shadden S, Lekien F, Paduan J, Chavez F, Marsden JE (2009) The correlation between surface drifters and coherent structures based on high-frequency radar data in monterey bay. Deep Sea Research Part II: Topical Studies in Oceanography 56(3-5):161-172

Stewart RH, Joy JW (1974) HF radio measurements of surface currents. In: Deep Sea Research and Oceanographic Abstracts, Elsevier, vol 21, pp 1039-1049

Taupier-Letage I, Millot C (1986) General hydrodynamical features in the ligurian sea inferred from the dyome experiment. Oceanologica Acta 9(2):119-131

Whelan C, Hubbard M (2015) Benefits of multi-static on HF radar networks. In: OCEANS 2015-MTS/IEEE Washington, IEEE, pp 1-5

Yang J, Wang R, Shi Y, Xu X, Li S, Wang C, Zhou H, Wen B, Wu S (2014) Dual-use multistatic $\mathrm{HF}$ ocean radar for current mapping and ship tracking. IEICE Electronics Express pp 1120140,281

Yoshikawa Y, Matsuno T, Marubayashi K, Fukudome K (2007) A surface velocity spiral observed with adcp and hf radar in the tsushima strait. Journal of Geophysical Research: Oceans $112(\mathrm{C} 6)$ 